\title{
Siniketun (Vulpes lagopus) nahkaominaisuuksien, rehuhyötysuhteen ja koon väliset geneettiset tunnusluvut
}

\author{
Riitta Kempe $^{1)}$, Nita Koskinen ${ }^{2)}$ ja Ismo Strandén ${ }^{1)}$ \\ ${ }^{1)}$ MTT Maa- ja elintarviketalouden tutkimuskeskus, Biotekniikka ja elintarviketutkimus, Alimentum, \\ 31600 Jokioinen, riitta.kempe@mtt.fi \\ ${ }^{2)}$ MTT Maa- ja elintarviketalouden tutkimuskeskus, Kotieläintuotannon tutkimus, Tervamäentie 179, \\ 05840 Hyvinkää, nita.koskinen@luovaoy.fi
}

\section{Tiivistelmä}

Siniketun tärkeimmät jalostustavoitteet ovat pentue- ja nahkakoko sekä nahan laatu (värin puhtaus, tummuus ja yleislaatu). Merkittävin nahasta maksettavaan hintaa vaikuttava tekijä on koko. Rehu on puolestaan tuotantosuunnan suurin kustannustekijä ja rehukustannusten oletetaan nousevan edelleen. Tämän vuoksi siniketun parempi rehuhyötysuhde on nousemassa uudeksi tärkeäksi jalostustavoitteeksi. Rehun tehoton käyttö lisää myös sonnasta aiheuttavaa ravinnekuormitusta ja nostaa turkistuotannon hiilijalanjälkeä.

Rehuhyötysuhteen perinnöllisen vaihtelun suuruus ja yhteydet muihin tuotanto-ominaisuuksiin on tunnettava tarkoin ennen kuin rehuhyötysuhde voidaan lisätä siniketun jalostusohjelmaan. Näin pyritään välttämään valinnan aiheuttamat mahdolliset negatiiviset sivuvaikutukset. Tämän tutkimuksen tavoitteena oli estimoida nahan laatuominaisuuksien, rehuhyötysuhteen ja koko-ominaisuuksien väliset geneettiset ja fenotyyppiset korrelaatiot. Tutkimusaineisto $(n=2076)$ kerättiin vuosien 2005 2006 aikana MTT:n Kannuksen koetilalla. Geneettiset tunnusluvut arvioitiin monen ominaisuuden eläinmalleilla REML-menetelmään perustuvalla DMU-ohjelmalla.

Nahan koolla oli nykyisen valintaohjelman valossa korkea suotuisa geneettinen korrelaatio eläimen gradeerauskoon, loppupainon, nenänpäästä hännän tyveen mitatun vartalon pituuden ja kasvunopeuden kanssa sekä keksinkertainen positiivinen korrelaatio eläimen kuntoluokan kanssa. Eläimen pituuden ja lihavuutta kuvaavan kuntoluokan välinen geneettinen korrelaatio oli kuitenkin niin matala, että niitä voidaan pitää eri ominaisuuksina. Geneettiset korrelaatiot nahan laatuominaisuuksien ja koko-ominaisuuksien välillä eivät poikenneet nollasta. Rehuhyötysuhteen ja turkin värin puhtauden välillä oli matala geneettinen korrelaatio, minkä vuoksi rehuhyötysuhteen suora valinta voi lisätä punerrusta turkin värisävyyn, mikä alentaa laatua. Nahan pituudella ja kasvunopeudella oli suotuisa geneettinen korrelaatio rehuhyötysuhteeseen, mutta melko korkea epäedullinen geneettinen yhteys rehunkulutukseen.

Nykyinen suuren eläin- ja nahkakoon korostaminen valinnassa parantaa epäsuorasti myös rehuhyötysuhdetta, mutta se ei todennäköisesti vähennä oleellisesti rehun kulutusta. Yhä pitempien nahkojen tuottaminen suosii nopeakasvuisia, kookkaita ja lihavia yksilöitä. Nämä ominaisuudet ovat puolestaan yhteydessä lisääntyneeseen rehunkulutukseen. Valinnassa voitaisiinkin painottaa enemmän vartalon pituutta kuin suurta gradeerauskokoa. Myös rehuhyötysuhde olisi kiinnostavaa laskea pituuden ja rehunkulutuksen suhteena. Eläinten terveyden kannalta pitkän hoikan ketun jalostaminen on toivotumpi vaihtoehto kuin nahan pituuden lisääminen eläintä lihottamalla. Rehuhyötysuhteen, rehunkulutuksen, koon ja nahan laatuominaisuuksien väliset geneettiset yhteydet tulisi huomioida asianmukaisesti siniketun jalostusohjelmassa.

Asiasanat: kotieläinjalostus, turkiseläimet, korrelaatio, periytyvyysaste 


\section{Johdanto}

Rehut ovat turkistilan tuotantokustannusten suurin menoerä. Tälle ei näy muutosta, sillä rehujen hintataso ja rehunkustannus tuotettua nahkaa kohti ovat kasvaneet merkittävästi viime vuosina. Alustavien selvitysten mukaan eläinten välillä on melko paljon vaihtelua rehun hyväksikäyttökyvyssä. Rehuhyötysuhde on kuitenkin erittäin haastava ominaisuus mitata turkiselinkeinossa, koska eläin- ja työmäärä punnituksineen on hyvin suuri. Haasteista huolimatta tutkimuksen lähtöoletus oli, että sinikettujen parempi rehuhyötysuhde ja tarkentunut ruokinta vähentävät rehunkulutusta, ruokintakustannuksia ja lannasta aiheutuvaa ravinnekuormitusta siinä määrin, että se on taloudellisesti merkittävä mahdollisuus turkiselinkeinon kannattavuuden parantamiseen.

Viime vuosikymmenen aikana sinikettu on jalostunut isoksi ja lihavaksi eläimeksi, koska nahan hinta määräytyy pääasiassa nahan koon mukaan ja lihavuudella on positiivinen vaikutus nahan kokoon. Nykyinen jalostusohjelma ei kuitenkaan vielä tällä hetkellä huomioi lihavuuden vaikutusta ketun kokoon, lopulliseen nahan kokoon tai rehunkulutukseen. Tämä voi johtaa ongelmatilanteeseen, jossa lihavien eläinten gradeerauskoon ja nahan koon jalostusarvon ennusteet yliarvioidaan, jolloin valinta gradeeraus- ja/tai nahkakoon perusteella saattaa lisätä eläinten lihavuutta, rehun kulutusta ja rehukustannuksia tuotettua nahkaa kohden.

Tässä tutkimuksessa laskettiin nahan laatuominaisuuksien, rehuhyötysuhteen ja kokoominaisuuksien väliset fenotyyppiset ja geneettiset korrelaatiot. Tutkimusprojektin tavoitteena oli selvittää voidaanko jalostuksessa suosia rehunkäyttökyvyltään tehokkaita, rakenteeltaan kevyempiä, solakoita ja pitkärunkoisia kettuja, joista saadaan iso nahka.

\section{Aineisto ja menetelmät}

Tutkimusaineisto kerättiin MTT turkistalouden tutkimusaseman ja Keski-Pohjanmaan maaseutuopiston Kannuksen yksikön turkistiloilla keväällä 2005 ja 2006. Aineisto koostui noin 2076 siniketusta, jotka olivat syntyneet toukokuun puolivälin ja kesäkuun puolivälin välisenä aikana. Tutkimusaineistoon pyrittiin saamaan mahdollisimman paljon geneettistä vaihtelua eikä tutkittujen ominaisuuksien suhteen tehty valintaa. Aineiston ensimmäisen sukupolven isät $(n=48)$ paritettiin vähintään viiden eri naaraan $(n=241)$ kanssa. Yli neljän pennun pentueista muodostettiin uros-uros, uros-naaras ja naarasnaaras täyssisarpareja (n=1026), jotka kasvatettiin samassa häkissä. Täyssisarpareista 40\% kasvatettiin kahdessa eri varjotalossa ja $60 \%$ hallirakennuksessa. Tutkimukseen käytettyjen kettujen sukulaisuustiedot ( $\mathrm{n}=21307)$ saatiin Suomen Turkiseläinten Kasvattajain Liitosta. Koejärjestelyt on kuvattu tarkemmin Kempen ym. (2008, 2010, 2013) aikaisemmissa julkaisuissa.

Nahan laatuominaisuuksista koko, värin tummuus ja värin puhtaus mitattiin koneellisesti nahkalajittelun yhteydessä. Nahan koko $(\mathrm{cm})$ mitattiin koneellisesti kuonosta hännäntyveen. Värin tummuuden arvostelussa pienempi pikselimäärä kuvasi tummempaa nahkaa ja suurempi pikselimäärä vaaleampaa nahkaa. Värin puhtauden pienempi pikselimäärä kuvasi toivotumpaa sinistä värisävyä. Lisäksi ammattilajittelijat arvioivat silmämääräisesti jokaisen nahan peittävyyden ja nahan yleislaadun viisiluokkaisella asteikolla, jossa 1 oli huonoin ja 5 paras luokka. Siitoseläinten (48 isää ja 241 emää) nahka-arvosteluja ei voitu liittää tutkimusaineistoon. Siitoseläimet nahkottiin keväällä, jolloin niiden turkki ei ollut enää parhaimmillaan ja näin ollen vertailukelpoinen tuotantoeläinten talvinahkojen kanssa.

Gradeeraus eli elävän eläimen arvostelu tehtiin loka-marraskuussa noin kuukausi ennen nahkontaa. Eläimen koon arvioinnissa luokka 1 oli pienin ja luokka 5 suurin. Eläinten loppupaino, vartalon pituus nenästä hännän tyveen ja lihavuutta kuvaava kuntoluokka mitattiin nahkonnan yhteydessä. Kuntoluokituksessa käytettiin asteikkoa yhdestä viiteen: erittäin laiha (1), erittäin lihava (5) (Kempe ym. 2009).

Koe-eläimiä ruokittiin ruokahalun mukaan ja tavoitteena oli saavuttaa normaalia tilaruokintaa vastaava rajoittamaton ruokinta. Häkkikohtaisen kettuparin rehunkulutuksen seuranta perustui Farm Pilot -ruokintaohjelmaan (Tved Maskinbyg, Kolding, Tanska). Rehumäärää säädettiin rehujäämien ja vähentyneen tai lisääntyneen rehunkulutuksen mukaan. Rehunkulutuksen seurantaa tehtiin vieroituksesta nahkontaan. Siniketut punnittiin kolmen viikon välein: ensimmäinen punnitus tehtiin vieroituksen yhteydessä, kasvukauden aikana ketut punnittiin neljä kertaa ja viimeinen punnitus tehtiin nahkonnan yhteydessä. Keskimääräinen kasvunopeus (g/pv) laskettiin kaavalla: (jakson loppupaino jakson alkupaino)/kasvatuspäivien lukumäärä. Rehuhyötysuhde (kasvu/rehunkulutus) laskettiin kasvun ja täyssisarparin häkkikohtaisen rehunkulutuksen avulla: häkkiparin kasvu (g) jaettiin täyssisarparin vastaavan jakson rehunkulutuksella (g kuiva-ainetta). 
Varianssi- ja kovarianssikomponentit arvioitiin monen ominaisuuden eläinmalleilla DMUohjelmalla (Madsen ja Jensen 2000), joka perustuu restricted maximum likelihood (REML) menetelmään. Koko- ja nahkaominaisuuksien geneettiset korrelaatiot estimoitiin yksilötuloksista monen ominaisuuden eläinmallilla (1) kolme ominaisuutta kerralla:

$Y_{i j k l m n o}=\mu+h y_{i}+s_{j}+p_{k}+t_{l}+d_{m}+c_{n}+a_{o}+e_{i j k l m n o}$, jossa hy $\mathrm{i}_{\mathrm{i}}$ on talo-vuosi yhdysvaikutus (i=1-6), $\mathrm{s}_{\mathrm{j}}$ sukupuoli $(\mathrm{j}=1,2), \mathrm{p}_{\mathrm{k}}$ täyssisarpari, joka kasvatettiin samassa häkissä $(\mathrm{k}=1-3$; uros-uros, uros-naaras, naaras-naaras), $t_{1}$ syntymäajankohta $(1=1-4 ; 1=104-129,2=130-144,3=145-160$ ja 4=161-180 päivää

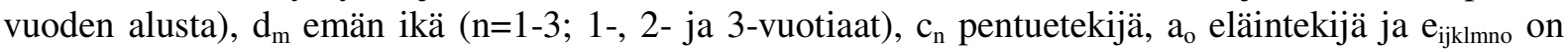
jäännöstekijä. Talo-vuosi, sukupuoli, täyssisarpari, syntymäajankohta ja emän ikä olivat kiinteitä tekijöitä. Pentue-, eläin- ja jäännöstekijä olivat mallin satunnaistekijöitä. Satunnaistekijät pentue-, eläin- ja jäännöstekijä oletettiin toisistaan riippumattomiksi ja normaalisti jakautuneiksi. Niiden keskiarvon oletettiin olevan nolla ja varianssien: $\operatorname{var}(\mathbf{c})=\mathbf{I} \otimes \mathbf{C}, \operatorname{var}(\mathbf{a})=\mathbf{A} \otimes \mathbf{G}$ ja $\operatorname{var}(\mathbf{e})=\mathbf{I} \otimes \mathbf{R}$, missä $\otimes$ on Kronecker tulo, I identiteettimatriisi, $\mathbf{C}$ pentuetekijän varianssi-kovarianssimatriisi, $\mathbf{G}$ ominaisuuksien välinen geneettinen varianssi-kovarianssimatriisi ja $\mathbf{R}$ ominaisuuksien jäännöstekijän varianssikovarianssimatriisi.

Rehuhyötysuhteen ja nahkaominaisuuksien väliset geneettiset ja fenotyyppiset korrelaatiot laskettiin monen ominaisuuden eläinmallilla (2):

$\mathrm{Y}_{i j l m n p q}=\mu+h y_{i}+p y_{j}+p d_{l}+t y_{m}+d y_{n}+c_{p}+a_{q}+e_{i j l m n p q}$, jossa $Y_{i j l m n p q}$ oli samassa häkissä kasvatetun täyssisarparin keskiarvo, hy $y_{i}$ oli talo-vuosi yhdysvaikutus $(i=1-6), p y_{j}$ pari-vuosi $(\mathrm{j}=1-6), p d_{l}$ parin (uros-uros, uros-naaras, naaras-naaras) ja emän iän yhdysvaikutus $(l=1-9), t y_{m}$ syntymäajankohta-vuosi $(m=1-7), d y_{n}$ emän iän ja vuoden yhdysvaikutus $(n=1-5), c_{p}$ pentuetekijä, $a_{q}$ eläintekijä ja $e_{i j l m n p q}$ jäännöstekijä. Pentue-, eläin- ja jäännöstekijän oletukset olivat samat kuin mallissa (1) paitsi, että eläimen korvasi täyssisarpari. Tämän vuoksi DMU:n aliohjelmaan, joka muodostaa sukulaisuusmatriisin käänteismatriisin $\left(A^{-1}\right)$, piti tehdä täyssisarkeskiarvojen käytön laskennassa huomioiva muutos. Kun havaintoina käytetään täyssisarten keskiarvoja, geneettinen varianssi, residuaalivarianssin ohella, on pienempi kuin yksilötuloksia käytettäessä (Kovac \& Groeneveld 1990).

\section{Tulokset ja tulosten tarkastelu}

Geneettiset ja fenotyyppiset korrelaatiot koko- ja nahkaominaisuuksien välillä on esitetty taulukossa 1. Nahan pituuden geneettiset korrelaatiot eläimen vartalon pituuden, elopainon ja gradeerauskoon välillä olivat odotetusti korkeita. Korkein geneettinen korrelaatio oli nahan pituuden ja elopainon välillä. Myös nahan pituuden ja gradeerauskoon välinen geneettinen korrelaatio oli lähes yhtä korkea. Nykyinen käytäntö, jossa nahan pituutta valitaan epäsuorasti gradeerauskoon avulla, on siis varsin tehokas ja toimiva.

Eläimen kuntoluokka (lihavuus) vaikuttaa olevan yhteydessä eläimen silmämääräisesti arvosteltavaan gradeerauskokoon sekä koneellisesti mitattavaan nahan pituuteen, sillä ominaisuuksien väliset geneettiset ja fenotyyppiset korrelaatiot olivat keskinkertaisia. Positiivisen korrelaation vuoksi lihavien eläinten gradeerauskoon ja nahan koon jalostusarvon nykyiset ennusteet saattavat olla hieman yliarvioituja, ja valinta gradeeraus- ja/tai nahkakoon perusteella suosii lihavia eläimiä.

Eläimen vartalon pituuden ja kuntoluokan välinen geneettinen korrelaatio ei poikennut nollasta, joten näitä muuttujia voidaan pitää eri ominaisuuksina. Näin ollen pituuskasvun ja rasvan varastoitumisen taustalla ovat erilaiset geneettiset säätelymekanismit. Jos kokoa valitaan vartalon pituuden perusteella, se ei lisää eläinten lihavuutta samoin kuin valinta gradeerauskoon perusteella. Vartalon pituuden geneettinen korrelaatio nahan pituuteen oli kuitenkin korkea, joten elävän eläimen pituusmittaus voisi olla käytäntöön soveltuva arvostelumenetelmä nahan pituuden epäsuoraan valintaan.

Koko-ominaisuuksien (nahan pituus, eläimen vartalon pituus, elopaino, kuntoluokka ja gradeerauskoko) geneettiset korrelaatiot nahan laatuominaisuuksiin (värin puhtaus, tummuus, peitinkarvan peittävyys ja laatu) olivat pääosin alhaisia tai korkeintaan keskinkertaisia. Koska estimaattien keskivirheet olivat korkeita, tulokset ovat vain suuntaa-antavia. Myös matalat tai lähellä nollaa olevat fenotyyppiset korrelaatiot viittaavat siihen, etteivät lihavuus ja suuri elopaino heikennä oleellisesti turkin laatuominaisuuksia.

Rehuhyötysuhteen, kasvunopeuden, rehunkulutuksen ja nahkaominaisuuksien väliset geneettiset ja fenotyyppiset korrelaatiot on esitetty taulukossa 2 . Rehuhyötysuhteen ja rehunkulutuksen välinen geneettinen korrelaatio oli odotettua vähäisempi (-0.07) eikä se poikennut nollasta. Rehunkulutuksen mittaus täyssisarparin häkkikeskiarvona ei ole yhtä tarkka arvio rehunkulutuksesta kuin yksittäi- 
seltä eläimeltä mitattuna, mikä todennäköisesti vaikuttaa jossain määrin tuloksiin suurempana jäännöstekijän varianssina kuin yksilömittatietoa käytettäessä. Nahan pituus ja kasvunopeus olivat suotuisasti kytkeytyneet rehuhyötysuhteen kanssa. Nahan pituutta painotetaan voimakkaasti nykyisissä jalostusvalinnoissa ja sen geneettinen korrelaatio rehuhyötysuhteen kanssa oli keskinkertainen (0.36). Toisaalta kasvunopeus ja nahan pituus olivat erittäin voimakkaasti korreloituneet rehunkulutuksen kanssa. Jos valinnassa painotetaan yksinomaan nopeaa kasvua ja kokoa, nousevat myös rehun kulutus ja ruokintakustannukset.

Rehuhyötysuhteen ja nahan laadun väliset geneettiset yhteydet olivat pääosin erittäin alhaisia. Paremman rehuhyötysuhteen valinta ei vaikuta merkittävästi turkin laatuun värin puhtautta lukuun ottamatta. Rehuhyötysuhteen valinta saattaa lisätä ei-toivottavaa punerrusta turkin väriin, mikäli tätä epäsuotuisaa yhteyttä ei huomioida jalostusohjelmassa.

\section{Johtopäätökset}

Kasvun, rehunkulutuksen, rehuhyötysuhteen ja koon optimointi on tärkeää turkiselinkeinossa. Nykyinen suuren eläin- ja nahkakoon painottaminen valinnassa parantaa epäsuorasti rehuhyötysuhdetta. Tätä kautta saavutettava parempi rehuhyötysuhde ei kuitenkaan vähennä merkittävästi rehun kulutusta ja tuotantokustannuksia, koska isojen nahkojen tuottaminen suosii nopeakasvuisia, suuria ja lihavia yksilöitä. Nämä ominaisuudet ovat suuren nahkakoon ohella yhteydessä korkeampaan rehunkulutukseen. Valinta yksinomaan paremman rehuhyötysuhteen perustella saattaa vaikuttaa vähäisessä määrin turkin laatuominaisuuksiin niin, että ei-toivottava punertava värisävy ja vaaleiden turkkien osuus lisääntyy.

Valinnassa voitaisiinkin painottaa enemmän vartalon pituutta kuin suurta gradeerauskokoa, sillä se vaikuttaa voimakkaasti eläimestä saatavan nahan pituuteen ja siitä maksettavaan hintaan. Pituuden kasvattamisella ei näyttäisi olevan epäedullisia vaikutuksia nahan laatuun eikä se lisää eläinten lihavuusriskiä. Eläinten terveyden kannalta, pitkän hoikan ketun jalostaminen on toivotumpi vaihtoehto kuin nahan pituuden lisääminen eläintä lihottamalla. Myös rehuhyötysuhde olisi kiinnostavaa laskea pituuden ja rehunkulutuksen suhteena.

Epäsuotuisien yhteyksien vuoksi rehuhyötysuhteen, rehunkulutuksen, kasvunopeuden, koon ja nahan laatuominaisuuksien väliset geneettiset yhteydet tulisi ottaa huomioon asianmukaisesti siniketun jalostusohjelmassa ja ominaisuuksien painokertoimissa.

\section{Kirjallisuus}

Kempe, R., Strandén, I., Koivula, M., Rekilä, T., Koskinen, N. \& Mäntysaari, E. 2008. Genetic parameters of feed efficiency and its relationships with feed intake, daily gain and animal size traits in Finnish blue fox (Alopex lagopus). Scientifur 32, 47-52.

Kempe, R., Koskinen, N., Peura, J., Koivula, M., Strandén, I. (2009) Body condition scoring method for blue fox (Alopex lagopus). Acta Agr. Scand. 59, 85-92.

Kempe, R., Koskinen, N., Mäntysaari, E. \& Strandén, I. 2010. The genetics of body condition and leg weakness in the blue fox (Alopex lagopus). Acta Agr. Scand. 60, 141-150.

Kempe, R., Koskinen, N., Mäntysaari, E. \& Strandén, I. 2013. Genetic parameters of pelt character, feed efficiency and size traits in Finnish blue fox (Vulpes lagopus). J. Anim. Breed. Genet. 130: 445-455.

Kovac, M. \& Groeneveld, E. 1990. Multivariate genetic evaluation in swine combining data from different testing schemes. Journal of Animal Science 68, 3 507-3 522.

Madsen, P. \& Jensen, J. 2000. Users guide to DMU, a package for analysing Multivariate Mixed Models. Danish Institute of Agricultural Sciences. Tjele. Denmark. 22 p. 
Taulukko 1. Siniketun koko- ja nahkaominaisuuksien väliset fenotyyppiset (alakolmio) ja geneettiset korrelaatiot (yläkolmio) sekä niiden keskivirhe $\left( \pm\right.$ S.E.) ${ }^{1,2}$

\begin{tabular}{|c|c|c|c|c|c|c|c|c|c|}
\hline & Nahkakoko & Pituus & Elopaino & BCS & Gradkoko & Puhtaus & Tummuus & Peittävyys & Laatu \\
\hline Nahkakoko & & $0,63 \pm 0,11$ & $0,74 \pm 0,08$ & $0,42 \pm 0,14$ & $0,72 \pm 0,09$ & $0,11 \pm 0,23$ & $-0,09 \pm 0,20$ & $0,20 \pm 0,21$ & $0,13 \pm 0,19$ \\
\hline Pituus & 0,47 & & $0,40 \pm 0,15$ & $0,04 \pm 0,18$ & $0,72 \pm 0,07$ & $0,34 \pm 0,21$ & $-0,19 \pm 0,20$ & $0,09 \pm 0,21$ & $0,28 \pm 0,18$ \\
\hline Elopaino & 0,60 & 0,40 & & $0,83 \pm 0,05$ & $0,74 \pm 0,09$ & $0,10 \pm 0,22$ & $-0,16 \pm 0,18$ & $0,12 \pm 0,20$ & $0,02 \pm 0,18$ \\
\hline BCS & 0,39 & 0,18 & 0,65 & & $0,51 \pm 0,13$ & $-0,25 \pm 0,22$ & $0,28 \pm 0,19$ & $-0,01 \pm 0,21$ & $0,00 \pm 0,20$ \\
\hline Gradkoko & 0,47 & 0,52 & 0,55 & 0,36 & & $0,37 \pm 0,23$ & $-0,01 \pm 0,20$ & $0,20 \pm 0,21$ & $0,25 \pm 0,19$ \\
\hline Puhtaus & 0,12 & 0,17 & 0,11 & 0,08 & 0,11 & & $-0,01 \pm 0,23$ & $0,16 \pm 0,25$ & $-0,07 \pm 0,23$ \\
\hline Peittävyys & 0,03 & 0,02 & $-0,04$ & $-0,05$ & $-0,01$ & $-0,01$ & $-0,15$ & & $-0,28 \pm 0,20$ \\
\hline Laatu & 0,02 & 0,12 & 0,04 & 0,02 & 0,09 & $-0,04$ & $-0,02$ & $-0,08$ & \\
\hline
\end{tabular}

${ }^{1}$ Geneettiset korrelaatiot, jotka poikkeavat nollasta enemmän kuin 1.96×S.E. on lihavoitu.

${ }^{2}$ Korrelaatiot laskettiin monen ominaisuuden eläinmallilla (1). Eläinkohtaisia havaintoja oli 1664-2060.

Nahkakoko=nahan pituus senttimetreinä, Pituus=eläimen vartalon pituus senttimetreinä, Elopaino=eläimen loppupaino, BCS=kuntoluokka ("lihavuus") nahkottaessa, Grad-

koko=elävän ketun gradeerauskoko, Puhtaus=turkin värin puhtaus (mitattu pikseleinä), Tummuus=turkin värin tummuus (mitattu pikseleinä), Peittävyys=peitinkarvan peittävyys, Laatu=nahan yleislaatu.

Taulukko 2. Rehuhyötysuhteen ja nahkaominaisuuksien väliset fenotyyppiset (alakolmio) ja geneettiset korrelaatiot (yläkolmio) sekä niiden keskivirhe ( \pm S.E.) ${ }^{1,2}$

\begin{tabular}{|c|c|c|c|c|c|c|c|c|}
\hline & Rehuhyötysuhde & Kasvunopeus & Rehunkulutus & Nahkakoko & Puhtaus & Tummuus & Peittävyys & Laatu \\
\hline Rehuhyötysuhde & & $0,53 \pm 0,08$ & $-0,07 \pm 0,05$ & $0,36 \pm 0,06$ & $-0,22 \pm 0,07$ & $0,21 \pm 0,05$ & $-0,07 \pm 0,04$ & $0,04 \pm 0,04$ \\
\hline Kasvunopeus & 0,46 & & $0,80 \pm 0,06$ & $0,70 \pm 0,11$ & $0,15 \pm 0,23$ & $0,10 \pm 0,20$ & $0,05 \pm 0,21$ & $0,16 \pm 0,20$ \\
\hline Rehunkulutus & $-0,26$ & 0,73 & & $0,55 \pm 0,15$ & $0,34 \pm 0,25$ & $0,01 \pm 0,23$ & $0,08 \pm 0,25$ & $0,19 \pm 0,23$ \\
\hline Nahkakoko & 0,11 & 0,54 & 0,50 & & $0,18 \pm 0,24$ & $-0,15 \pm 0,20$ & $0,24 \pm 0,21$ & $0,13 \pm 0,21$ \\
\hline Puhtaus & $-0,09$ & 0,08 & 0,17 & 0,17 & & $0,00 \pm 0,25$ & $0,17 \pm 0,27$ & $0,20 \pm 0,26$ \\
\hline Tummuus & 0,10 & 0,11 & 0,05 & $-0,02$ & 0,08 & & $-0,35 \pm 0,20$ & $0,19 \pm 0,21$ \\
\hline Peittävyys & $-0,09$ & $-0,06$ & 0,00 & 0,01 & 0,00 & $-0,16$ & & $-0,44 \pm 0,20$ \\
\hline Laatu & $-0,07$ & 0,04 & 0,11 & 0,06 & 0,01 & 0,00 & $-0,08$ & \\
\hline
\end{tabular}

${ }^{1}$ Geneettiset korrelaatiot, jotka poikkeavat nollasta enemmän kuin 1.96×S.E. on lihavoitu.

${ }^{2}$ Korrelaatiot laskettiin monen ominaisuuden eläinmallilla (2). Täyssisarparin häkkikeskiarvosta koostuvia havaintoja oli $782-1026$.

Rehuhyötysuhde, kasvunopeus ja rehunkulutus mitattiin jaksolla, joka alkoi elokuun puolivälissä ja loppui lokakuun puolivälissä (9 viikkoa).

Nahkakoko=nahan pituus senttimetreinä, Pituus=eläimen vartalon pituus senttimetreinä, Elopaino=eläimen loppupaino, BCS=kuntoluokka nahkottaessa, Gradkoko=elävän ketun gradeerauskoko, Puhtaus=turkin värin puhtaus (mitattu pikseleinä), Tummuus=turkin värin tummuus (mitattu pikseleinä), Peittävyys=peitinkarvan peittävyys, Laa$\mathrm{tu}=$ nahan yleislaatu. 